\title{
Indicadores de Desenvolvimento Sustentável no Vale do Rio Pardo
}

\author{
Emanuele Mantovani ${ }^{1}$ \\ Sílvio Cezar Arend ${ }^{2}$
}

\begin{abstract}
Resumo
Os conceitos de crescimento e desenvolvimento há muito vêm sendo debatidos sem que se chegue a um consenso a seu respeito. Ao incluir no debate o termo sustentável, ampliam-se as discussões e as visões acerca do que seria o desenvolvimento sustentável, mesmo sem se chegar a um conceito definitivo nem sobre como mensurá-lo. No entanto, tem-se clareza de que alguns indicadores podem contribuir com dados quantitativos. 0 objetivo deste trabalho é identificar indicadores que possam contribuir para mensurar o desenvolvimento no Vale do Rio Pardo. A coleta dos dados deu-se com base nas informações sistematizadas no Observatório do Desenvolvimento Regional, com indicadores distribuídos em três eixos: econômico, social e ambiental. A partir do cruzamento das informações apuradas, chegou-se à conclusão de que, sob a perspectiva da economia ambiental, os critérios de desenvolvimento do Vale do Rio Pardo são atendidos. Já sob a perspectiva da economia ecológica, os critérios são parcialmente atendidos, indicando que os aspectos que se referem à qualidade de vida, inclusão e infraestrutura são os principais pontos que devem ser melhorados, com o objetivo de promover o desenvolvimento sustentável no Vale do Rio Pardo.
\end{abstract}

Palavras-chave: Desenvolvimento regional. Desenvolvimento sustentável. Indicadores.

\begin{abstract}
The concepts of growth and development have long been debated without a consensus being reached on them. By including the term sustainable in the debate, discussions and visions about sustainable development are broadened, even without reaching a definitive concept or ways of measuring it. However, it is clear that some indicators can contribute with quantitative data. The objective of this work is to identify indicators that can contribute to measure development in the Vale do Rio Pardo. Data collection was based on the information systematized in the Regional Development Observatory, with indicators distributed in three axes: economic, social and environmental. From the intersection of the information obtained, it was concluded that from the perspective of the environmental economy the development criteria of the Vale do Rio Pardo are met. From the perspective of the ecological economy, the criteria are partially met, indicating that the aspects that refer to the quality of life, inclusion and infrastructure are the main points that must be improved with the objective of promoting sustainable development in the Vale do Rio Pardo.
\end{abstract}

Keywords: Regional development. Sustainable development. Indicators.

\section{Introdução}

\footnotetext{
${ }^{1}$ Doutoranda no Programa de Pós-Graduação em Desenvolvimento Regional (UNISC). Bolsista CAPES/PROSUC Modalidade I. manumontovani@gmail.com

${ }^{2}$ Doutor em Economia. Professor do Departamento de Ciências Econômicas e do Programa de Pós-Graduação em Desenvolvimento Regional da Universidade de Santa Cruz do Sul (UNISC). silvio@unisc. br
} 
A palavra desenvolvimento vem assumindo diferentes significados ao longo do tempo. Dialogando com temas como a redução da pobreza, a inclusão social, o crescimento econômico, a criação de novas tecnologias, novas formas de produção e de consumo, aquisição de bens de consumo, o desenvolvimento adquire diferentes enfoques de acordo com o contexto e a época. Quando se usa o termo desenvolvimento, ele quase nunca vem acompanhado de explicação ou sentido, porque se subentende que o seu significado seja bem compreendido. No entanto, isso não leva em consideração a pluralidade de sentidos que podem ser atribuídos ao termo "desenvolvimento", embora se tenha clareza de que ele não é consensual.

Em uma visão globalizada, o desenvolvimento está associado ao crescimento econômico, ao avanço tecnológico e ao progresso. Embora esta seja uma noção de sentidos múltiplos, um ponto sobre o qual se tem clareza é que, muito mais do que crescimento econômico sob o ponto de vista quantitativo, o desenvolvimento pressupõe não só o crescimento e o progresso, mas também a erradicação da pobreza e a melhoria de indicadores qualitativos no que se refere ao bem-estar e à qualidade de vida.

Para termos mais clareza acerca da noção de desenvolvimento, a seguir vamos abordar o conceito a partir dos pressupostos teóricos de alguns autores que já tentaram, de alguma forma, elaborar uma noção de desenvolvimento que não tenha a pretensão de ser hegemônica, mas que proponha uma forma ampla de pensar este conceito e que seja universalmente viável.

Para Sen (2000), o desenvolvimento está relacionado, diretamente, com a expansão das liberdades para as pessoas. O autor entende que, em que pesem o crescimento econômico e as dimensões globais, um grande número de pessoas ainda tem negadas liberdades elementares, diretamente relacionadas com a pobreza, que as privam de ter atendidas suas necessidades mais básicas. Segundo o autor, um crítico da economia ortodoxa, o enfoque nas liberdades contrasta com as visões que identificam o desenvolvimento a partir da industrialização ou do progresso tecnológico. Entre as principais privações de liberdade estão a fome, a subnutrição, a pobreza, a falta de acesso à educação e à saúde de qualidade, falta de serviços básicos, como saneamento, além da falta de emprego, de segurança - tanto econômica quanto social -, e privação de direitos civis e políticos (SEN, 2000). 
De acordo com esta visão, a ação das pessoas é influenciada não só pelas oportunidades econômicas, mas também pelas liberdades política e social e por boas condições de saúde e educação. De acordo com esta perspectiva, são cinco as liberdades que, interligadas, são instrumentais ao desenvolvimento: as liberdades políticas, as disponibilidades econômicas, as oportunidades sociais, as garantias de transparência e a segurança. Neste sentido, as liberdades não são apenas um fim, mas também um meio de se chegar ao desenvolvimento por meio das liberdades políticas, condições sociais e econômicas, acesso a serviços de saúde e segurança e educação de qualidade (SEN, 2000).

Na concepção de Furtado (1988), o conceito de desenvolvimento pode ser abordado a partir de três principais concepções (que se inter-relacionam de forma complexa), que são o aumento na eficiência do sistema de produção, a satisfação das necessidades básicas e os objetivos relacionados ao uso de recursos naturais. Esta inter-relação é complexa, uma vez que conceitos como bem-estar e a própria noção de necessidades básicas são subjetivos. Por outro lado, o autor entende que os problemas ambientais decorrentes da exploração dos recursos naturais pelo modo de produção capitalista não podem ser solucionados, simplesmente, pelo progresso da tecnologia (FURTADO, 1974).

Outro autor que se debruça sobre o tema do desenvolvimento e joga luz ao debate é Sachs (2004), que parte da diferença entre desenvolvimento e crescimento econômico. Embora compreenda que o segundo é fundamental, entende que o primeiro vai além da acumulação da riqueza. Neste sentido, o autor aborda ainda a necessidade da redução das desigualdades, além da inclusão das noções de equidade e solidariedade como forma de superar o que chama de "economicismo redutor" e avançar no sentido da redução da pobreza e da busca de soluções que não comprometam o bem-estar das gerações futuras (SACHS, 2004).

$\mathrm{Na}$ tentativa de equacionar bem-estar, qualidade de vida, inclusão, crescimento econômico e preservação dos recursos é que surge o conceito de desenvolvimento sustentável. Se chegar a um consenso sobre o conceito de desenvolvimento já era um desafio, ao incluir o tema da sustentabilidade, a complexidade se amplifica. De forma geral, pode-se dizer que as noções de desenvolvimento sustentável são baseadas nos mesmos conceitos de desenvolvimento já citados: liberdade, inclusão, bem-estar e crescimento econômico, com o 
acréscimo da variável ambiental, a fim de conciliar os interesses econômicos e a inclusão social com os limites ambientais.

A definição de desenvolvimento sustentável ganha espaço a partir da divulgação do Relatório da Comissão Mundial do Meio Ambiente e Desenvolvimento da ONU, em 1987, conhecido como Relatório Brundtland, como o desenvolvimento que permite atender às necessidades do presente, porém sem comprometer a capacidade de atender às necessidades das gerações futuras (CECHIN, 2010).

O desenvolvimento sustentável emerge de um contexto no qual se reconhece que o progresso técnico tem potencial para relativizar os limites ambientais, mas não os elimina. Portanto, o crescimento econômico é condição necessária, mas não suficiente, para a eliminação da pobreza e das desigualdades (MAY, 2003). No entanto, as interpretações acerca do termo ainda são divergentes. Embora o conceito de desenvolvimento sustentável não seja preciso e unânime, há uma tendência em aceitá-lo, de forma geral, em razão de sua simplicidade e, também, porque há certo consenso a respeito da necessidade de se combinar eficiência, equidade e proteção ao meio ambiente (MUELLER, 2007; MUELLER, 2005).

Por se tratar de um conceito ainda aberto e que se propõe a diversas interpretações, o termo desenvolvimento sustentável tem sido usado para as mais variadas definições, que priorizam tanto o meio ambiente quanto a economia, a partir de diferentes indicadores. Neste sentido, ao abordar o desenvolvimento sustentável no Vale do Rio Pardo, este artigo traz as duas principais correntes de pensamento acerca desse desenvolvimento, uma orientada para o mercado, e a outra orientada para os limites do meio ambiente, propondo um conjunto de indicadores que podem oferecer subsídios para uma análise do desenvolvimento no Vale do Rio Pardo.

Assim, as próximas seções deste artigo apresentam as duas principais abordagens que se referem ao desenvolvimento sustentável, a utilização de indicadores, com apresentação e análise de indicadores de desenvolvimento do Vale do Rio Pardo, e, por fim, as considerações finais.

\section{0 desenvolvimento sustentável na abordagem da economia ambiental neoclássica}


A economia ambiental tem origem na economia clássica, voltada ao mercado, que tem na base do desenvolvimento sustentável a tecnologia e a capacidade de substituir o capital natural pelo capital construído. É uma visão que prioriza o desenvolvimento econômico e o antropocêntrico. Por isso, a questão ambiental passou a fazer parte da agenda econômica clássica a partir do momento em que houve a preocupação com as limitações impostas pelo meio ambiente à expansão do capitalismo e ao próprio crescimento econômico.

Alguns eventos foram determinantes para a incorporação da questão ambiental às discussões econômicas: a acentuação da poluição e da degradação no primeiro mundo e a consciência de que as regiões industriais estavam excedendo a capacidade do meio ambiente; a crise do petróleo de 1973, que pôs em dúvida a viabilidade do crescimento, em função do uso de energia e de recursos naturais; e o relatório do Clube de Roma, que abordava as consequências do crescimento demográfico e a necessidade de acomodar a economia e a sociedade às restrições impostas pelo meio ambiente (MUELLER, 2007).

A economia do meio ambiente tem como metas para o desenvolvimento sustentável a manutenção e ampliação da qualidade de vida, a redução da pobreza e a manutenção do capital natural, que, para esta concepção, pode ser substituído pelo capital construído e pela tecnologia. Esta noção tem centralidade na economia ambiental neoclássica, voltada aos problemas ambientais da economia de mercado e que considera o meio ambiente passivo, sujeito a impactos que podem ser revertidos através da tecnologia. Esta abordagem não considera a possibilidade de que o esgotamento de um recurso possa restringir a expansão da economia (MUELLER, 2005).

Foi a partir de meados da década de 1960, com a ampliação dos movimentos ambientalistas, que a dimensão ambiental passou a ser considerada na economia neoclássica. Esta dimensão está fundamentada no conceito de externalidades de Pigou ${ }^{3}$, que são as falhas produzidas pelo próprio mercado no processo de acumulação. Assim, a questão ambiental passa a ser tratada como uma externalidade que pode ser internalizada pelo processo de produção por meio da valoração monetária dos ativos ambientais e com a inclusão dos custos sociais. A valoração monetária estabelece um nível de poluição aceitável, bem como a

\footnotetext{
${ }^{3}$ Foi o primeiro a estabelecer o conceito de externalidade em economia, em 1920. Depois, em relação às externalidades ambientais, propôs a fórmula "o poluidor paga", que visa internalizar os custos relativos à degradação ambiental e passou a ser um dos princípios básicos que formam o Direito Ambiental (MONTIBELLER-FILHO, 2001).
} 
possibilidade de despoluir, pagar um imposto pelo impacto gerado, ou adquirir um bônus que conceda, antecipadamente, o direito de poluir (MONTIBELLER - FILHO, 2001).

No entanto, quando se trata de reparação de danos ou indenizações, um dos principais desafios é determinar o valor a ser pago. A economia ecológica propõe alguns métodos diretos e indiretos de valoração por meio da soma do valor do ativo ambiental, da valoração de contingência para reparação de danos, do método que considera a relação entre o benefício gerado e o custo ambiental, ou através da utilização de preços de mercado para bens ambientais, por exemplo (MERICO, 2002).

Neste sentido, é importante atentar para o fato de que um dos principais fundamentos da sustentabilidade é o atendimento das necessidades das gerações futuras. No entanto, o método não responde ao critério de equidade intergeracional do desenvolvimento sustentável, pois não é possível mensurar o valor do bem para as gerações futuras.

Mas a pergunta que se faz é como determinar o valor de um bem ambiental, ou que critérios usar para determinar este valor, uma vez que a própria concepção acerca do valor de determinado bem é relativa e se altera de acordo com a região e a população? Neste sentido, evidencia-se ser impossível quantificar corretamente e medir o valor dos bens ambientais para as gerações futuras. Além disso, a abordagem econômica neoclássica não dá conta das questões relacionadas ao desenvolvimento sustentável, uma vez que não consegue, através da valoração monetária, internalizar as externalidades.

\section{0 ecodesenvolvimento e a perspectiva da economia ecológica}

A outra abordagem que se refere ao desenvolvimento sustentável é a da economia ecológica, baseada em dois princípios: o primeiro é a ecologia geral, de visão sistêmica, para a qual a economia é apenas uma parte de um sistema maior; o outro é o da capacidade de suporte, que é a limitação dos recursos naturais, para o que propõe um novo conceito, o do ecodesenvolvimento, em substituição ao desenvolvimento sustentável. Os fundamentos dessa corrente têm origem na Primeira Conferência das Nações Unidas sobre Meio Ambiente, realizada em Estocolmo, em 1972, que põe o meio ambiente na pauta, contrapondo duas posições: uma que considera o crescimento como prioridade, pregando que o avanço tecnológico poderia neutralizar as externalidades produzidas, e outra que põe em xeque este 
modelo econômico, cujos danos são considerados irreversíveis do ponto de vista ambiental. Após a Conferência - que apontou problemas ambientais urgentes -, o termo ecodesenvolvimento foi usado pela primeira vez.

A perspectiva do ecodesenvolvimento entende o crescimento como necessário, porém ele deve ser includente e favorável ao meio ambiente. Trata-se de um desenvolvimento endógeno, autossuficiente, orientado para as necessidades e em harmonia com a natureza. Ou seja, a abordagem está fundamentada na equalização dos objetivos sociais, ambientais e econômicos (SACHS, 2003).

Para a economia ecológica, os bens naturais não podem ser substituídos; portanto, o crescimento do sistema econômico deve se adequar ao limite de uso desses recursos, de modo a evitar perdas que sejam irreversíveis. Para esta corrente, a economia deve funcionar considerando os limites ambientais e estabelecendo um ponto de equilíbrio para o seu crescimento de modo sustentável. É preciso levar em consideração tanto a capacidade dos ecossistemas quanto os custos ambientais e benefícios da expansão econômica (MERICO, 2002; MAY, 2003).

Neste sentido, para a economia ecológica, a natureza não pode ser substituída por tecnologia; portanto, não se deve utilizar recursos em taxas superiores à produtividade sustentável. Além disso, deve-se minimizar o uso de energia e a produção de rejeitos, considerar todo o custo ambiental de extração, produção e consumo e promover a duração máxima dos recursos através do reúso, conserto e reciclagem dos produtos. A economia ecológica adota uma perspectiva crítica à valoração monetária do meio ambiente, pois considera tecnicamente difícil estabelecer valores atualizados, plausíveis a todas as externalidades, muitas das quais são desconhecidas, incertas e, até mesmo, irreversíveis.

A economia ecológica apresenta uma proposta ecodesenvolvimentista que vê os problemas ambientais como decorrência de padrões de consumo insustentáveis e defende o controle de mercado para preservar estratégias locais de desenvolvimento.

Para a abordagem ecodesenvolvimentista, o desenvolvimento socioambiental é fundamentado: a) na sustentabilidade social, com a redução das desigualdades; b) na sustentabilidade econômica, com a gestão eficiente dos recursos e fluxo regular do investimento; c) na sustentabilidade ecológica, por meio do regramento no que diz respeito à utilização dos recursos, produção de resíduos e instrumentos para o cumprimento das regras; 
d) na sustentabilidade espacial, a partir de uma configuração mais equilibrada e melhor distribuição territorial; e) na sustentabilidade cultural, com planejamento participativo do desenvolvimento local, com políticas que orientem a ação do homem.

Para que o ecodesenvolvimento se torne operacional, são necessárias algumas précondições, como o profundo conhecimento das culturas e dos ecossistemas, o envolvimento das populações locais e um modelo institucional diferente do atual, que privilegia a lógica do mercado. O ecodesenvolvimento é uma proposta relativamente incompatível com o capitalismo e a economia de mercado. Por isso, ele pode oferecer soluções em escala local, mas não funciona como um modelo geral de desenvolvimento por não ser compatível com as instituições vigentes. Mesmo assim, a economia ecológica e o ecodesenvolvimento representam as mais importantes abordagens alternativas e críticas à economia ambiental e ao desenvolvimento sustentável de mercado.

\section{Indicadores de desenvolvimento no Vale do Rio Pardo}

Pelo que foi produzido em termos de pesquisa e conhecimento, até o momento, sabese que, além de ser um conceito em aberto, a sustentabilidade é imensurável. No entanto, algumas ferramentas podem ser úteis para o desenvolvimento de pesquisa, planejamento e implementação de políticas públicas e para a tomada de decisões no que se refere ao desenvolvimento sustentável, tanto na esfera pública quanto na privada. As definições acerca de sustentabilidade ainda são genéricas e pouco precisas; por isso, não há um conceito de sustentabilidade que seja universalmente aceito. Além disso, as estatísticas que se referem ao tema dão conta apenas de problemas pontuais, como o desmatamento, e não atingem uma esfera macro. São esses os principais fatores que dificultam a mensuração da sustentabilidade e do desenvolvimento.

Os indicadores são medidas, geralmente quantitativas, usadas para quantificar ou operacionalizar um conceito teórico. Portanto, além da base teórica, um indicador deve ser específico para o objeto que está sendo mensurado, de fácil entendimento e atualizável, de forma que se possa constituir uma série histórica. Existem diferentes tipos de indicadores, os quais podem ser absolutos, relativos; apontar relação esforço/resultado, fluxo/estoque, 
eficiência/eficácia/efetividade; ou compor uma média de vários indicadores (CARVALHO; BARCELOS, 2010).

Em relação ao desenvolvimento, a principal função dos indicadores é servir como instrumento de avaliação para mensurar o resultado da atividade econômica no que se refere à qualidade de vida. Neste sentido, o que se vê, atualmente, com o uso do Produto Interno Bruto (PIB) para mensurar a economia, por exemplo, não atende a questões importantes como a qualidade de vida e o bem-estar da sociedade. Medir a renda de um país não é suficiente, porque bem-estar tem um sentido muito mais amplo do que a medida monetária (MERICO, 2002).

No caso do PIB, por exemplo, a utilização deste indicador para medir riqueza é controversa, uma vez que ele só considera a adição de bens e serviços vendidos e comprados, sem distinguir o que é benéfico para a sociedade. Desta forma, eventos como desastres ambientais, catástrofes, acidentes de trânsito e a própria violência urbana "contribuem" para o aumento do PIB, uma vez que geram aumento na demanda por bens e serviços como materiais de construção, equipamentos de segurança, grandes obras de reparo (como, por exemplo, na reconstrução de uma ponte derrubada por uma enxurrada) e serviços de saúde (MERICO, 2002).

Ou seja, tudo o que se pode vender aumenta o PIB, gerando crescimento, mas não, necessariamente, desenvolvimento sustentável. Por outro lado, não é possível contabilizar a perda de bem-estar decorrente do aumento no PIB. Atividades e recursos que contribuem para o bem-estar (como viver em uma cidade arborizada) não podem ser contabilizados. A mensuração do PIB não considera, por exemplo, a desigualdade e a pobreza. No entanto, mesmo que não haja uma medida que seja consenso, a utilização de alguns índices e indicadores ocupam lugar importante para a fiscalização e são aliados das entidades ambientalistas como instrumentos de pressão sobre governos e organizações (VEIGA, 2010).

Neste sentido, a teoria do decrescimento faz uma crítica ao sistema vigente, que se apoia no crescimento do PIB para mensurar crescimento econômico e, consequentemente, a melhoria no nível de vida. Para a teoria do decrescimento, este não é um modelo sustentável, uma vez que os recursos naturais são limitados. Portanto, a melhoria da qualidade de vida deve ser obtida sem aumento no consumo. Os teóricos do decrescimento defendem a 
utilização de indicadores como IDH, a Pegada Ecológica e o Índice de Saúde Social como forma de mensurar toda a variedade de riquezas possíveis (LOUETTE, 2009).

Ao extinguir recursos fundamentais à manutenção da vida, o modelo vigente de desenvolvimento, focado apenas no crescimento econômico, agrava as desigualdades e ameaça nossa sobrevivência. É necessário que seja estabelecida uma nova contabilidade a partir de um pacto social, ambiental e político em escala mundial. Neste sentido, vários países têm trabalhado na construção de indicadores que ajudem a mensurar qualidade de vida, saúde e bem-estar.

Levando em consideração a dificuldade de mensurar o desenvolvimento sustentável, a proposta deste artigo é inferir sobre como alguns indicadores podem contribuir para mensurá-lo na região do Vale do Rio Pardo. Para essa análise, foram considerados os 23 municípios que fazem parte do Corede Vale do Rio Pardo. A região corresponde a 4,7\% do total do território do Rio Grande do Sul, e tem, conforme o Censo de 2010 do IBGE, 418.141 habitantes, o que corresponde a 3,91\% do total de habitantes do Estado. No Vale do Rio Pardo, região marcada pela grande incidência de pequenas propriedades rurais que se dedicam ao cultivo de tabaco, $36,87 \%$ da população estão concentrados na zona rural, enquanto que $63,13 \%$, na zona urbana. Santa Cruz do Sul é o município polo da região e concentra o maior número de indústrias beneficiadoras de tabaco em folha. A forte presença da cadeia produtiva do tabaco influenciou na configuração do município, que concentra as principais organizações sindicais e de classe que representam este setor, além de órgãos federais e estaduais, como

No caso específico deste estudo, os indicadores que estão sendo considerados foram divididos em três eixos: econômico, social e ambiental. Para cada eixo, foram selecionados diferentes indicadores, como distribuição de renda, PIB, Valor Adicionado Bruto; Índice de Desenvolvimento Humano (IDH) e vulnerabilidade social; esgotamento sanitário, abastecimento de água e destino do lixo. Os dados foram coletados no portal do Observatório do Desenvolvimento Regional, onde estão sistematizados a partir de diferentes fontes, como o Instituto Brasileiro de Geografia e Estatística (IBGE).

O primeiro eixo a ser analisado é o econômico, para o qual foram selecionados os indicadores de distribuição de renda, PIB e PIB per capita e Valor Adicionado Bruto. O Produto Interno Bruto (PIB) é um indicador macroeconômico que tem por finalidade mensurar o nível de atividade econômica de uma dada região (município, estado ou país), durante um 
determinado período de tempo, em que são somados todos os bens e serviços finais produzidos num dado período de tempo. Deste modo, o PIB per capita consiste no PIB dividido pelo número total de habitantes de um município, estado ou país. Já o Valor Adicionado Bruto (VAB) corresponde à diferença entre as receitas (vendas) e os insumos adquiridos de terceiros (custos), o que representa o valor adicionado oriundo da atividade produtiva (OBSERVATÓRIO DO DESENVOLVIMENTO REGIONAL, 2018).

Os dados apresentados na Tabela 1, que se referem à distribuição de renda entre os municípios do Vale do Rio Pardo e do Rio Grande do Sul, mostram uma situação de similaridade no que se refere às faixas de renda apresentadas. No entanto, o que pode ser observado é que o Vale do Rio Pardo apresenta maior concentração de pessoas com renda de até dois salários mínimos, média de 79,02\%, enquanto que no Rio Grande do Sul a média de pessoas com esta faixa de renda é de $75,71 \%$. Nas faixas de renda superior a dois salários mínimos, os dados se invertem: enquanto que a média no Rio Grande do Sul é de $27,08 \%$ de pessoas, no Vale do Rio Pardo, a média de pessoas que ganha mais de dois salários mínimos é de $20,98 \%$.

Tabela 1 - Distribuição de renda

\begin{tabular}{lcc}
\hline Valor - Salário Mínimo (SM) & Rio Grande do Sul (\%) & VRP (\%) \\
\hline Menos de $1 / 2$ & $16,9 \%$ & $18,74 \%$ \\
De $1 / 2$ a 1 & $26,27 \%$ & $28,77 \%$ \\
De 1 a 2 & $30,54 \%$ & $31,51 \%$ \\
De 2 a 3 & $11,28 \%$ & $10,06 \%$ \\
De 3 a 5 & $8,16 \%$ & 6,36 \\
De 5 a 10 & $5,18 \%$ & $3,32 \%$ \\
Mais de 10 & $2,46 \%$ & $1,24 \%$ \\
\hline
\end{tabular}

Fonte: Elaborado pela autora a partir de dados do IBGE disponíveis no Observatório do Desenvolvimento Regional (2018).

Partindo do pressuposto de que o PIB e o PIB per capita podem ser usados como indicadores para mensurar o crescimento econômico, tendo como base os anos de 2013, 2014 e 2015 , do primeiro para o segundo ano, houve um aumento de $13,11 \%$. Em relação à participação do Vale do Rio Pardo no PIB do Estado, de 2013 para 2014, aumentou em mais 
de 40\%. No entanto, de 2014 para 2015, houve aumento de apenas 0,44\% e redução de 30,38\% na participação do PIB estadual. No que se refere ao PIB per capita, nos três anos analisados, o Vale do Rio Pardo apresenta índices superiores à média do Rio Grande do Sul. Portanto, a partir dos pressupostos que utilizam o PIB como indicador de desenvolvimento, pode-se dizer que os índices apresentados pelo Vale do Rio Pardo são, relativamente, satisfatórios no período, pois, ainda que tenha apresentado baixa dinâmica de crescimento, de 2014 para 2015, o PIB per capita se manteve acima da média do Estado (Tabela 2).

Tabela 2 - PIB e PIB per capita VRP/RS (2013 - 2015)

\begin{tabular}{lllll}
\hline \multicolumn{2}{c}{ INDICADOR } & \multicolumn{1}{c}{$\mathbf{2 0 1 3}$} & \multicolumn{1}{c}{$\mathbf{2 0 1 4}$} & \multicolumn{1}{c}{$\mathbf{2 0 1 5}$} \\
\hline \multirow{3}{*}{ PIB } & VRP & 13.734 .887 .091 & 15.534 .976 .095 & 15.603 .861 .430 \\
& RS & 332.292 .726 .085 & 265.056 .416 .296 & 381.985 .142 .734 \\
& VRP/RS & $4,13 \%$ & $5,86 \%$ & $4,08 \%$ \\
PIB per capita & VRP & $31.446,20$ & $35.423,10$ & $35.445,03$ \\
& RS & $28.764,55$ & $23.651,46$ & $33.960,36$ \\
& VRP/RS & $109,32 \%$ & $149,77 \%$ & $104,37 \%$ \\
\hline
\end{tabular}

Fonte: Elaborado pela autora a partir de dados da Fundação de Economia e Estatística (FEE) e IBGE disponíveis no Observatório do Desenvolvimento Regional (2018).

O terceiro indicador utilizado para mensurar o desenvolvimento econômico no Vale do Rio Pardo é o Valor Adicionado Bruto. Assim como o PIB, para esta análise, foram considerados os resultados do VAB de 2013, 2014 e 2015 no Vale do Rio Pardo e no Rio Grande do Sul. Os dados apresentados na Tabela 3 indicam crescimento do VAB no Vale do Rio Pardo nos três anos analisados; no entanto, enquanto que, de 2013 a 2014, o crescimento foi de 10,77\%; de 2014 para 2015, foi de 1,11\%. No Rio Grande do Sul, o primeiro período analisado apresentou aumento de $8,11 \%$, enquanto que o segundo cresceu, em média, 7,58\%. Os dados demonstram uma queda no VAB do Vale do Rio Pardo em relação ao Rio Grande do Sul. Se, em 2013, o Valor Adicionado na região correspondia a 4,06\% do Estado; em 2015, o valor caiu para 3,91\%. 
Tabela 3 - Valor Adicionado Bruto VRP/RS (2013 - 2015)

\begin{tabular}{llll}
\hline \multicolumn{1}{c}{ ABRANGÊNCIA } & \multicolumn{1}{c}{$\mathbf{2 0 1 3}(\mathbf{R} \mathbf{)}$} & \multicolumn{1}{c}{$\mathbf{2 0 1 4}$ (R\$) } & \multicolumn{1}{c}{$\mathbf{2 0 1 5}$ (R\$) } \\
\hline VRP & 11.653 .667 .273 & 12.907 .790 .303 & 13.050 .047 .972 \\
RS & 286.665 .159 .991 & 309.927 .137 .595 & 333.410 .230 .032 \\
VRP/RS & $4,06 \%$ & $4,16 \%$ & $3,91 \%$ \\
\hline
\end{tabular}

Fonte: Elaborado pela autora a partir de dados da Fundação de Economia e Estatística (FEE) disponíveis no Observatório do Desenvolvimento Regional (2018).

O segundo eixo utilizado para mensurar o desenvolvimento no Vale do Rio Pardo refere-se à inclusão social. Para este, foram analisados os dados disponíveis no Observatório do Desenvolvimento que se referem ao Índice de Desenvolvimento Humano Municipal (IDHM), que agrega as mesmas três dimensões do IDH Global: a oportunidade de viver uma vida longa e saudável, a de ter acesso ao conhecimento e a de possuir um padrão de vida que garanta as necessidades básicas, representadas por saúde, educação e renda, e do Índice de Desenvolvimento Socioeconômico (IDESE), que avalia a situação socioeconômica dos municípios gaúchos quanto à Educação, Renda e Saúde, considerando aspectos quantitativos e qualitativos do processo de desenvolvimento. A diferença em relação ao IDHM está na divulgação anual do índice em nível municipal. Neste sentido, os indicadores utilizados são diferentes, porém agrupados nos mesmos três blocos que no IDHM.

Além dos dois índices de desenvolvimento, foram analisados os dados referentes às famílias cadastradas no Programa Bolsa Família, política pública de transferência de renda para todas as famílias com renda per capita mensal de até $\mathrm{R} \$ \mathbf{8 5 , 0 0}$ e famílias com renda per capita mensal entre $\mathrm{R} \$ 85,01$ e $\mathrm{R} \$ 170,00$, desde que tenham crianças ou adolescentes de 0 a 17 anos, e os dados referentes à Vulnerabilidade Social, que apontam o número de pessoas em situação de extrema pobreza.

Na Tabela 4, são apresentados os dados do IDESE (geral, educação, saúde e renda) relativos ao ano de 2013 e do IDHM (geral, renda, educação e longevidade) relativos ao ano de 2010. No que se refere ao IDESE, os números apresentados, ainda que estejam abaixo da média do Rio Grande do Sul em todas as variáveis, estão muito próximos. Além disso, o índice geral e os blocos de educação e renda indicam desenvolvimento médio, e o bloco da saúde, desenvolvimento alto. No caso do IDHM, os dados são semelhantes. Os números do VRP ficam um pouco abaixo da média estadual, ainda que estejam muito próximos. O bloco de educação 
é o único que apresenta índice considerado de baixo desenvolvimento humano, enquanto que o bloco longevidade é o único considerado muito alto desenvolvimento humano. Os demais se situam entre as faixas de médio a alto desenvolvimento.

Tabela 4 - IDESE (2013) e IDHM (2010) - Vale do Rio Pardo e Rio Grande do Sul

\begin{tabular}{llll}
\hline \multicolumn{1}{c}{ INDICADOR } & \multicolumn{2}{c}{ VRP } & RS \\
\hline IDESE & 0,688 & 0,734 & \\
IDESE EDUCAÇÃO & 0,642 & 0,693 & \\
IDESE SAÚDE & 0,814 & 0,833 & \\
IDESE RENDA & 0,610 & 0,675 & \\
IDHM & 0,68 & 0,746 \\
IDHM - RENDA & 0,70 & 0,769 \\
IDHM - EDUCAÇÃO & 0,54 & 0,642 \\
IDHM - LONGEVIDADE & 0,82 & 0,84 & \\
\hline
\end{tabular}

Fonte: Elaborado pela autora a partir de dados do Programa das Nações Unidas para o Desenvolvimento (PNUD) e da Fundação de Economia e Estatística (FEE), disponíveis no Observatório do Desenvolvimento Regional (2018).

Já na Tabela 5, são apresentados os dados referentes ao Programa Bolsa Família. Considerando o total de beneficiários no Vale do Rio Pardo, o total de famílias atendidas aumentou 1,36\% de 2013 para 2014 e reduziu 6,37\% de 2014 para 2015. Considerando a média de famílias atendidas no período, esta foi de 21.484 , o que corresponde a $15,44 \%$ do total de domicílios do Vale do Rio Pardo. Em relação ao Rio Grande do Sul, este índice é de 12,2\%, o que põe o VRP em mais de 3 pontos percentuais acima da média do estado.

Tabela 5 - Beneficiários Bolsa Família VRP/RS (2013 - 2010)

\begin{tabular}{llll}
\hline ABRANGÊNCIA & $\mathbf{2 0 1 3}$ & $\mathbf{2 0 1 4}$ & $\mathbf{2 0 1 5}$ \\
\hline VRP & 21.756 & 22.050 & 20.646 \\
RS & 455.421 & 434.715 & 427.939
\end{tabular}

Fonte: Elaborado pela autora a partir de dados da SAGI/Ministério do Desenvolvimento Social disponíveis no Observatório do Desenvolvimento Regional (2018).

Outro dado apresentado na Tabela 6, que tem relação com a inclusão no Vale do Rio Pardo, diz respeito à vulnerabilidade social. Comparando os dados disponíveis de 2000 e 2010, disponíveis no Observatório do Desenvolvimento Regional, percebe-se que o número de 
pessoas em situação de extrema pobreza reduziu em mais de $50 \%$. No entanto, ainda ficou abaixo da redução média apresentada no Rio Grande do Sul, que foi de cerca de $60 \%$.

Tabela 6 - Vulnerabilidade social VRP/RS (2000 - 2010)

\begin{tabular}{lllllll}
\hline \multicolumn{1}{c}{ ABRANGÊNCIA } & \multicolumn{3}{c}{ POPULAÇÃO TOTAL } & \multicolumn{3}{c}{ \% DOS EXTREMAMENTE POBRES } \\
\hline \multirow{2}{*}{ VRP } & $\mathbf{2 0 0 0}$ & $\mathbf{2 0 1 0}$ & VARIAÇÃO & $\mathbf{2 0 0 0}$ & $\mathbf{2 0 1 0}$ & VARIAÇÃO \\
RS & 396.911 & 418.414 & $5,08 \%$ & 10,25 & 4,42 & $-56,87$ \\
& 10.187 .798 & 10.693 .929 & 4,96 & 5,01 & 1,98 & $-60,47$ \\
\hline
\end{tabular}

Fonte: Elaborado pela autora a partir de dados do Programa das Nações Unidas para o Desenvolvimento (PNUD) disponíveis no Observatório do Desenvolvimento Regional (2018).

No terceiro e último eixo de análise do desenvolvimento do Vale do Rio Pardo, são considerados dados relativos à questão ambiental, mais especificamente no que se refere ao abastecimento de água, destino do lixo e esgotamento sanitário.

A Tabela 7 apresenta o número de domicílios de acordo com a rede de abastecimento de água, sendo que no Vale do Rio Pardo mais de $75 \%$ são abastecidos pela rede geral, contra 85\% no Rio Grande do Sul. Já os domicílios abastecidos por poço ou nascente no VRP somam $24,04 \%$, contra $14,13 \%$ no Estado, o que pode estar relacionado com o número de domicílios na zona rural, no Vale do Rio Pardo.

Tabela 7 - Abastecimento de água VRP/RS (2010)

\begin{tabular}{lcccccc}
\hline ABRANGÊNCIA & \multicolumn{2}{c}{ REDE GERAL } & \multicolumn{2}{c}{ POÇO OU NASCENTE } & \multicolumn{2}{c}{ OUTRAS FORMAS } \\
\hline & n. & $\%$ & n. & $\%$ & n. & $\%$ \\
VRP & 106.827 & 75,45 & 34.036 & 24,04 & 731 & 0,52 \\
RS & 3.071 .715 & 85,33 & 508.774 & 14,13 & 19.115 & 0,53 \\
\hline
\end{tabular}

Fonte: Elaborado pela autora a partir de dados do IBGE disponíveis no Observatório do Desenvolvimento Regional (2018).

Outro indicador no qual o Vale do Rio Pardo está abaixo da média do Estado se refere ao destino do lixo (Tabela 8). Enquanto que na média estadual mais de $90 \%$ dos domicílios têm coleta de lixo, na região, este número não chega a $85 \%$. Por outro lado, no VRP são mais de $15 \%$ dos domicílios que ainda queimam ou enterram o lixo, enquanto que no Rio Grande do Sul esta média é de cerca de 7\%, ou seja, menos da metade do índice registrado na região.

\section{Tabela 8 - Destino do lixo VRP/RS (2010)}




\begin{tabular}{lcccccc}
\hline ABRANGÊNCIA & \multicolumn{2}{c}{ COLETA DE LIXO } & \multicolumn{2}{c}{ QUEIMA OU ENTERRA } & \multicolumn{2}{c}{ OUTRO DESTINO } \\
\hline \multirow{2}{*}{ VRP } & n. & $\%$ & n. & $\%$ & n. & $\%$ \\
RS & 118.127 & 83,43 & 51.528 & 15,20 & 1.939 & 1,37 \\
\hline
\end{tabular}

Fonte: Elaborado pela autora a partir de dados do IBGE disponíveis no Observatório do Desenvolvimento Regional (2018).

Por fim, o último dado observado na análise do desenvolvimento no Vale do Rio Pardo, sob o ponto de vista ambiental, diz respeito ao esgotamento sanitário. Neste ponto, enquanto que no Estado o número de domicílios que contam com rede geral de coleta ou esgoto pluvial passa de $48 \%$, no Vale do Rio Pardo este número não chega a 38\%. Por outro lado, a região supera em 10 pontos percentuais a média estadual de domicílios com fossa séptica, sistema pelo qual a matéria esgotada passa por um processo de tratamento ou decantação. Porém, na região, a média de domicílios sem banheiro é, praticamente, o dobro do estado. Em relação a outras formas de esgotamento (fossa rústica ou ligado a uma vala a céu aberto), a média do Vale do Rio Pardo é um pouco superior à do estado, embora haja pouca diferença. Portanto, se por um lado o número de domicílios com tratamento de esgoto sanitário na região seja superior à média do estado, também são superiores os índices de domicílios sem banheiro ou com valas a céu aberto (Tabela 9).

Tabela 9 - Esgotamento sanitário VRP/RS (2010)

\begin{tabular}{lcccccccc}
\hline ABRANGÊNCIA & \multicolumn{2}{c}{$\begin{array}{c}\text { REDE GERAL OU } \\
\text { ESGOTO PLUVIAL }\end{array}$} & \multicolumn{2}{c}{ FOSSA SÉPTICA } & \multicolumn{2}{c}{ OUTRA FORMA } & \multicolumn{2}{c}{$\begin{array}{c}\text { SEM BANHEIRO OU } \\
\text { SANITÁRIO }\end{array}$} \\
\hline \multirow{2}{*}{ VRP } & n. & $\%$ & n. & $\%$ & n. & $\%$ & n. & $\%$ \\
RS & 53.453 & 37,75 & 49.043 & 34,64 & 37.155 & 26,24 & 1.943 & 1,37 \\
& 1.731 .575 & 48,10 & 952.483 & 26,46 & 891.932 & 24,78 & 23.614 & 0,66 \\
\hline
\end{tabular}

Fonte: Elaborado pela autora a partir de dados do IBGE disponíveis no Observatório do Desenvolvimento Regional (2018).

Os dados exibidos mostram que, apesar de apresentar índices muito próximos aos do estado em praticamente todos os indicadores analisados, a Região do Vale do Rio Pardo apresenta média inferior em relação ao Rio Grande do Sul. Os resultados podem indicar déficits estruturais importantes no que se refere à renda, à qualidade de vida e à infraestrutura; no entanto, mesmo diferentes conjuntos de indicadores não são suficientes 
para sugerir desenvolvimento ou subdesenvolvimento, uma vez que não há sequer uma ancoragem conceitual rígida sobre estes termos, mas diferentes perspectivas que permitem olhar os territórios a partir de diferentes aspectos.

\section{Considerações finais}

Os dados apurados no Observatório do Desenvolvimento Regional evidenciam a dificuldade em estabelecer indicadores que apontem para o desenvolvimento sustentável. A perspectiva da economia ambiental, fundamentada no desenvolvimento econômico, não considera dados importantes relativos à qualidade de vida e à preservação do meio ambiente. Já sob a ótica da economia ecológica, que leva em consideração esses aspectos, são muitas as variáveis que podem ser consideradas quando se fala em desenvolvimento. Por isso, mesmo os dados tradicionalmente utilizados em escala mundial para medir o desenvolvimento, sejam índices sintéticos como o IDH, ou isolados, não dão conta da complexidade dessa análise e não oferecem uma resposta que possa indicar se uma região é ou não desenvolvida.

No levantamento realizado, fica evidenciado que a utilização de indicadores de crescimento econômico e renda não é suficiente para mensurar o desenvolvimento de uma região. No caso do Vale do Rio Pardo, especificamente, ainda que o volume apurado no PIB tenha apresentado dinâmica de crescimento superior à média do Rio Grande do Sul, em outros indicadores, os quais se referem à inclusão e ao meio ambiente, a região apresenta resultados inferiores às médias apuradas no estado.

Apesar de indicar crescimento no PIB e no PIB per capita superior à média estadual, o Vale do Rio Pardo apresenta dinâmica de crescimento inferior no Valor Adicionado Bruto. Além disso, no caso do IDESE e do IDHM, apesar de a região apresentar índices que apontam de médio a alto desenvolvimento, estes ainda estão abaixo das médias do estado. Cabe notar, também, que, apesar do PIB acima da média e do bom desempenho no IDESE e no IDHM, a região apresenta um grande número de pessoas em situação de vulnerabilidade social e mais de $15 \%$ da população cadastrada no Programa Bolsa Família, o que evidencia que o crescimento do PIB não seja necessariamente responsável por proporcionar mais renda e inclusão social. 
No terceiro e último eixo analisado, os dados sobre abastecimento de água, coleta de lixo e esgotamento sanitário também indicam que, apesar do bom desempenho no PIB, no IDESE e IDHM, a infraestrutura de água, saneamento e coleta de lixo do Vale do Rio Pardo ainda apresenta desenvolvimento abaixo da média do estado.

De forma geral, pode-se inferir que, no Vale do Rio Pardo, a forte presença da indústria de beneficiamento de tabaco, nos municípios de Santa Cruz do Sul e Venâncio Aires, pode ser a responsável pelo aumento do valor do PIB na região. Porém, a baixa industrialização, e até mesmo a estagnação de outros municípios, acaba repercutindo na baixa de alguns indicadores em relação ao estado.

Assim, cabe notar que, sob a perspectiva da economia ambiental, que privilegia o desenvolvimento econômico, os critérios de desenvolvimento do Vale do Rio Pardo são atendidos. Já sob a perspectiva da economia ecológica, que considera e inclusão e o meio ambiente, pode-se dizer que os critérios são parcialmente atendidos. Portanto, a redução nas disparidades entre os municípios, a redução da pobreza, a inclusão social e o investimento em infraestrutura de qualidade devem ser os principais pontos a serem melhorados para que o Vale do Rio Pardo se encaminhe, dentro de critérios específicos, para o desenvolvimento sustentável.

\section{Referências}

CARVALHO, P. G. M. de; BARCELLOS, F. C. Mensurando a sustentabilidade. In: Economia do meio ambiente: teoria e prática. 2. ed. Rio de Janeiro: 2010. P. 180-220.

CECHIN, Andrei. A natureza como limite da economia: a contribuição de Nicholas GeorgescuRoegen. São Paulo: SENAC-SP, 2010.

FURTADO, Celso. Desenvolvimento. In: CAIDEN, G.; CARAVANTES G. Reconsideração do conceito de desenvolvimento. Caxias do Sul: EDUSC, 1988. P.1-13.

O mito do desenvolvimento econômico. 2. ed. Rio de Janeiro: Paz e Terra, 1974.

LOUETTE, Anne (org.). Indicadores de Nações: uma contribuição ao diálogo da sustentabilidade. Gestão do conhecimento. São Paulo: Willis Harman House, 2007. MAY, P.; LUSTOSA, M. C.; VINHA, V. Economia do meio ambiente: teoria e prática. Rio de Janeiro: Elsevier, 2003. 
MANTOVANI, Emanuele. Microempreendedorismo Individual e Redes de Sociabilidade: uma análise da construção social do Microempreendedor Individual em Santa Cruz do Sul (RS). 2018. Dissertação (Mestrado - Programa de Pós-Graduação em Desenvolvimento Regional) Universidade de Santa Cruz do Sul, Santa Cruz do Sul, 2018.

MERICO, Luiz F. Introdução à economia ecológica. Blumenau: FURB, 1996

MONTIBELLER Filho, Gilberto. O mito do desenvolvimento sustentável. Meio ambiente e custos sociais no moderno sistema produtor de mercadorias. Florianópolis: UFSC, 2001.

MUELLER, Charles C. O Debate dos Economistas sobre a Sustentabilidade - uma avaliação sob a ótica da Análise do Processo Produtivo de Georgescu-Roegen. Est. Econômicos I, São Paulo, v. 35, n. 4, p. 687-713, 2005.

. Os economistas e as relações entre o sistema econômico e o meio ambiente. Brasília:

EdUnB; Finatec, 2007.

OBSERVATÓRIO DO DESENVOLVIMENTO REGIONAL (OBSERVA DR). Disponível em: http://observadr.org.br/portal. Acesso em: 23 abril 2018

SACHS, Ignacy. Caminhos para o desenvolvimento sustentável. Org. Paula Yone Stroh - Rio de Janeiro: Garamond, 2003.

. Desenvolvimento: includente, sustentável, sustentado. Rio de Janeiro: Garamond, 2004.

SEN, Amartya. Desenvolvimento como liberdade. São Paulo: Companhia das Letras, 2000.

VEIGA, José Eli da. Desenvolvimento sustentável: o desafio do século XXI. Rio de Janeiro: Garamond, 2010. 